\title{
PENDEKATAN ADAPTIVE NEURO FUZZY SEBAGAI ALTERNATIF BAGI BANK INDONESIA DALAM MENENTUKAN TINGKAT INFLASI DI INDONESIA
}

\author{
Armaini Akhirson \\ Fakultas Ekonomi, Universitas Gunadarma \\ armaini@staff.gunadarma.ac.id \\ Brahmantyo Heruseto \\ Fakultas Ekonomi, Universitas Gunadarma
}

\begin{abstract}
In this uncertain current economic condition, research and inflation rate modelling are considered necessary to give an estimate and prediction of inflation rates in the future. Adaptive Neuro Fuzzy approach is a combination of Neural Network and Fuzzy Logic. This study aims to describe the movement of inflation (output variable) so it can be estimated by observing four Indonesian macro-economic data, namely the exchange rate, money supply, interbank interest rates, and the output gap (input variable). Observation period started from the data in 2001 to 20113. After the learning process is complete, fuzzy systems generate 45 fuzzy rules that can define the input-output behavior. The results of this study indicated a fairly high degree of accuracy with an average error rate is 0.5315 .
\end{abstract}

Keywords: estimation of inflation, exchange rate, money suply, PUAB, output gap, fuzzy.

\begin{abstract}
ABSTRAK
Dalam kondisi ekonomi yang tidak menentu seperti saat ini, penelitian dan pemodelan tingkat inflasi dipandang perlu untuk memberikan perkiraan dan prediksi tingkat inflasi di masa depan. Pendekatan Adaptive Neuro Fuzzy adalah kombinasi dari Neural Network dan Fuzzy Logic. Penelitian ini bertujuan untuk menggambarkan pergerakan inflasi (variabel output) sehingga dapat diperkirakan dengan cara mengamati empat data ekonomi makro Indonesia, yaitu nilai tukar, jumlah uang beredar, tingkat suku bunga antar bank, dan output gap (variabe input). Periode pengamatan dimulai dari 2001 ${ }_{1}$ hingga 20113. Setelah learning process selesai, sistem fuzzy menghasilkan 45 fuzzy rules yang dapat menentukan perilaku input-output. Hasil penelitian ini menunjukkan tingkat akurasi yang cukup tinggi dengan tingkat kesalahan rata-rata 0,5315.
\end{abstract}

Kata kunci: estimasi inflasi, nilai tukar, jumlah uang beredar, PUAB, output gap, fuzzy 


\section{PENDAHULUAN}

Kestabilan inflasi merupakan prasyarat bagi pertumbuhan ekonomi yang berkesinambungan yang pada akhirnya memberikan manfaat bagi peningkatan kesejahteraan masyarakat. Pentingnya pengendalian inflasi didasarkan pada pertimbangan bahwa inflasi yang tinggi dan tidak stabil memberikan dampak negatif kepada kondisi sosial ekonomi.

Inflasi yang tinggi akan menyebabkan pendapatan riil masyarakat akan terus turun sehingga standar hidup dari masyarakat turun dan akhirnya menjadikan semua orang, terutama orang miskin, bertambah miskin. Inflasi yang tidak stabil akan menciptakan ketidakpastian (uncertainty) bagi pelaku ekonomi dalam mengambil keputusan. Pengalaman empiris menunjukkan bahwa inflasi yang tidak stabil akan menyulitkan keputusan masyarakat dalam melakukan konsumsi, investasi dan produksi, yang pada akhirnya akan menurunkan pertumbuhan ekonomi.

Berdasarkan data terkini dari Bank Indonesia, dapat dilihat bahwa selisih antara inflasi aktual dan target inflasi menimbulkan error yang cukup signifikan. Pada kondisi ekonomi yang tidak menentu seperti sekarang, maka penelitian dan permodelan tingkat inflasi dipandang perlu untuk memberikan estimasi dan prediksi tingkat inflasi dimasa yang akan datang.

Tabel 1

Target Inflasi Pemerintah

\begin{tabular}{lcc}
\hline Tahun & Target Inflasi & Inflasi Aktual \\
\hline 2001 & $4-6 \%$ & $12,55 \%$ \\
2002 & $9-10 \%$ & $10,03 \%$ \\
2003 & $9 \pm 1 \%$ & $5,06 \%$ \\
2004 & $5,5 \pm 1 \%$ & $6,40 \%$ \\
2005 & $6 \pm 1 \%$ & $17,11 \%$ \\
2006 & $8 \pm 1 \%$ & $6,60 \%$ \\
2007 & $6 \pm 1 \%$ & $6,59 \%$ \\
2008 & $5 \pm 1 \%$ & $11,06 \%$ \\
2009 & $4,5 \pm 1 \%$ & $2,78 \%$ \\
2010 & $5 \pm 1 \%$ & $6,96 \%$ \\
\hline
\end{tabular}

Penelitian ini bertujuan untuk menjelaskan pergerakan inflasi (variabel output) sehingga bisa di estimasi dengan mengamati empat data makro ekonomi Indonesia yaitu nilai tukar, jumlah uang beredar, suku bunga PUAB dan output gap (variabel input) menggunakan pendekatan adaptive neuro fuzzy, yaitu perpaduan antara jaringan syaraf tiruan dan logika fuzzy, dimana perpaduan keduanya diharapkan akan memberikan hasil yang akurat.

\section{KAJIAN PUSTAKA}

Agung et al. (2003) melakukan pengujian terhadap 29 variabel yang memungkinkan memiliki kandungan informasi terhadap inflasi. Dari hasil pengujian disimpulkan bahwa variabel-variabel yang meliputi nilai tukar Rp/USD, jumlah uang 
beredar, suku bunga PUAB dan output gap memiliki kandungan informasi yang dapat dijadikan sebagai prediktor pergerakan tingkat inflasi.

\section{Nilai Tukar}

Secara garis besar ada dua macam sistem nilai tukar (kurs), yaitu sistem kurs mengambang (floating exchange rate system) dan sistem kurs tetap (fixed exchange rate system). Jika nilai tukar mata uang suatu negara ditetapkan berdasarkan mekanisme pasar, maka negara tersebut dikatakan menganut sistem mengambang. Sebaliknya jika nilai tukar ditetapkan pemerintah maka sistem yang digunakan adalah sistem kurs tetap. Namun ada juga negara yang membiarkan nilai mata uangnya berada pada mekanisme pasar dan jika pergerakan mata tukarnya melampaui batas, pemerintah melakukan intervensi. Sistem seperti ini disebut sistem nilai tukar terkendali (managed floating exchange rate) (Manurung \& Rahardja 2004).

\section{Uang Beredar}

Jumlah uang beredar merupakan uang yang berada di masyarakat. Setidaknya terdapat dua pendekatan untuk mendefinisikan jumlah uang beredar. Kedua definisi disusun berdasarkan pendekatan transaksional (transactional approach) dan pendekatan likuiditas (liquidity approach). Pendekatan transaksional memandang jumlah uang beredar yang dihitung adalah jumlah uang yang dibutuhkan untuk keperluan transaksi. Pendekatan tersebut digunakan untuk menghitung jumlah uang beredar dalam arti sempit (narrow money) yang dikenal dengan $\mathrm{M}_{1}$. Di Indonesia yang termasuk dalam $\mathrm{M}_{1}$ adalah uang kartal dan uang giral. Pendekatan likuiditas mendefinisikan uang beredar adalah jumlah uang untuk kebutuhan transaksi ditambah uang kuasi (quasi money). Pertimbangannya adalah sekalipun uang kuasi merupakan aset finansial yang kurang likuid dibanding $\mathrm{M}_{1}$ tetapi sangat mudah diubah menjadi uang yang dapat digunakan untuk kebutuhan transaksi. Pendekatan ini digunakan untuk menghitung jumlah uang beredar dalam arti luas (broad money) yang dikenal dengan $\mathrm{M}_{2}$, yang terdiri atas $\mathrm{M}_{1}$ ditambah dengan uang kuasi. Di Indonesia yang dimaksud dengan uang kuasi adalah simpanan rupiah dan valuta asing milik penduduk pada sistem moneter yang untuk sementara waktu kehilangan fungsinya sebagai alat tukar (Manurung \& Rahardja 2004).

\section{Suku Bunga Pasar Uang Antar Bank}

Pasar Uang Antar Bank (PUAB) pada dasarnya merupakan pinjaman jangka pendek oleh suatu bank kepada bank lainnya dalam rangka memenuhi kewajiban proses kliring (Manurung \& Rahardja 2004). Selama satu tahun selalu ada hari-hari dimana sebuah bank mengalami kalah kliring. Kalah kliring merupakan proses pemindahbukuan dana yang harus dikeluarkan dari bank tersebut lebih besar dari dana yang masuk. Bank yang mengalami kalah kliring harus menutupi kekurangan dana tersebut pada hari itu juga agar tidak mendapat sanksi dari bank sentral. Untuk menutupi kekurangan tersebut, bank-bank yang mengalami kalah kliring dapat meminjam kepada bank lainnya. Jangka waktu pelunasan hanya 1 hari disebut one day call money (overnight). Pasar uang antar bank disebut juga interbank call money. 


\section{Output Gap}

Output gap didefinisikan sebagai persentase deviasi output aktual dari potensialnya (Tjahjono et al., 2010). Output gap merupakan selisih antara actual output dengan potential outputyang terjadi dalam suatu perekonomian. Output potensial dan output gap bukanlah variabel yang dapat diobservasi, melainkan harus diestimasi berdasarkan informasi pada variabel-variabel relevan yang bersifat observable (Bagian SSR Direktorat Riset Ekonomi dan Kebijakan Moneter BI 2000: 1). Metoda perhitungan ouput potensial yang paling sering digunakan selama ini adalah dengan mengunakan pendekatan mekanis Hodrick-Presscott (HP) filter. Pendekatan ini menjadi populer terutama karena kepraktisannya.

HP filter merupakan suatu metoda penghalusan (smoothing method) yang banyak digunakan untuk memperoleh estimasi komponen trend jangka panjang dari suatu series ekonomi makro. Metoda ini pertama kali digunakan oleh Hodrick dan Prescott untuk menganalisis siklus bisnis Amerika Serikat pasca perang dunia II.

\section{Inflasi}

Laju inflasi merupakan fenomena ekonomi yang lazim terjadi pada suatu perekonomian. Inflasi akan menjadi suatu persoalan ekonomi yang serius manakala berlangsung dalam jangka waktu yang panjang dan terus menerus serta berada pada level yang tinggi. Secara teoritis, inflasi diartikan dengan meningkatnya harga-harga barang secara umum dan terus menerus (Yuliadi 2008). Kenaikan harga pada sekelompok kecil barang belum bisa dikatakan sebagai inflasi. Demikian juga perubahan harga yang terjadi sekali saja juga belum bisa dikatakan sebagai inflasi.

\section{Adaptive Neuro Fuzzy}

Neuro-fuzzy adalah gabungan dari dua sistem yaitu sistem logika fuzzy dan jaringan syaraf tiruan. Sistem neuro-fuzzy berdasar pada sistem inferensi fuzzy yang dilatih menggunakan algoritma pembelajaran yang diturunkan dari sistem jaringan syaraf tiruan. Dengan demikian, sistem neuro-fuzzy memiliki semua kelebihan yang dimiliki oleh sistem inferensi fuzzy dan sistem jaringan syaraf tiruan. Dari kemampuannya untuk belajar maka sistem neuro-fuzzy sering disebut sebagai ANFIS (adaptive neuro fuzzy inference systems).

ANFIS (adaptive neuro fuzzy inference systems) adalah arsitektur yang secara fungsional sama dengan fuzzy model sugeno. Asritektur ANFIS juga sama dengan jaringan syaraf tiruan dengan fungsi radial dengan sedikit batasan tertentu. Bisa dikatakan ANFIS adalah suatu metoda yang mana dalam melakukan penyetelan aturan-aturan digunakan algoritma pembelajaran terhadap sekumpulan data. ANFIS juga memungkinkan aturan-aturan untuk beradaptasi (Kusumadewi 2002).

Berdasarkan arsitekturnya, struktur ANFIS terdiri dari lima lapisan dengan fungsi yang berbeda untuk tiap lapisannya. Tiap lapisan terdiri dari beberapa simpul yang dilambangkan dengan kotak dan lingkaran. Lambang kotak menyatakan simpul adaptif yang bearti nilai parameternya dapat berubah dengan pembelajaran, sedangkan lambang lingkaran menyatakan simpul nonadaptif yang nilainya tetap. 
Lapisan pertama, semua simpul pada lapisan ini adalah simpul adaptif (parameter dapat berubah) dengan fungsi simpul:

$\mathrm{O}_{1, \mathrm{i}}=\left\{\begin{array}{l}\mu_{\mathrm{A}_{\mathrm{i}}}\left(\mathrm{x}_{2}\right) ; \mathrm{i}=1,2 \\ \mu_{\mathrm{B}_{\mathrm{i}-2}}\left(\mathrm{x}_{2}\right) ; \mathrm{i}=3,4\end{array}\right.$

Penjelasan dari persamaan satu, $\mathrm{x}$ dan y adalah masukan pada simpul i, Ai (atau Bi-2) adalah fungsi keanggotaan masing-masing simpul. Simpul O1,i berfungsi untuk menyatakan derajat keanggotaan tiap masukan terhadap himpunan fuzzy A dan B. Fungsi keanggotaan yang dipakai adalah jenis generalized bell atau kurva lonceng. Parameter a, b, c, pada fungsi keanggotaan dinamakan parameter premis yang adaptif.

Lapisan kedua, semua simpul pada lapisan ini adalah nonadaptif parameter (tetap). Fungsi simpul ini adalah mengalikan setiap sinyal masukan yang datang. Fungsi simpul:

$\mathrm{O}_{2, \mathrm{i}}=\mathrm{w}_{\mathrm{i}}=\mu_{\mathrm{A}_{\mathrm{j}}}\left(\mathrm{x}_{1}\right) \cdot \mu_{\mathrm{B}_{\mathrm{k}}}\left(\mathrm{x}_{2}\right)$ 2

Tiap keluaran simpul menyatakan derajat pengaktifan (firing strength) tiap aturan fuzzy. Fungsi ini dapat diperluas apabila bagian premis memiliki lebih dari dua himpunan fuzzy. Banyaknya simpul pada lapisan ini menunjukkan banyaknya aturan yang dibentuk

Lapisan ketiga, setiap simpul pada lapisan ini adalah simpul nonadaptif yang menampilkan fungsi derajat pengaktifan ternormalisasi (normalized firingstrength) yaitu rasio keluaran simpul ke-i pada lapisan sebelumnya terhadap seluruh keluaran lapisan sebelumnya, dengan bentuk fungsi simpul:

$\mathrm{O}_{3, \mathrm{i}}=\overline{\mathrm{w}}_{\mathrm{i}}=\frac{\mathrm{w}_{\mathrm{i}}}{\sum \mathrm{w}}=\frac{\mathrm{w}_{\mathrm{i}}}{\mathrm{w}_{1}+\ldots+\mathrm{w}_{4}}$ 3

Lapisan ke empat setiap simpul pada lapisan ini adalah simpul adaptif dengan fungsi simpul:

$\mathrm{O}_{4, \mathrm{i}}=\overline{\mathrm{w}}_{\mathrm{i}} \cdot \mathrm{f}_{\mathrm{i}}=\overline{\mathrm{w}}_{\mathrm{i}}\left(\mathrm{p}_{\mathrm{i}} \mathrm{x}_{1}+\mathrm{q}_{\mathrm{i}} \mathrm{x}_{2}+\mathrm{r}_{\mathrm{i}}\right)$

Lapisan kelima,pada lapisan ini hanya ada satu simpul tetap yang fungsinya untuk menjumlahkan semua masukan. Fungsi simpul:

$\mathrm{O}_{5}=\sum \overline{\mathrm{w}}_{\mathrm{i}} \cdot \mathrm{f}_{\mathrm{i}}=\mathrm{y}$

\section{Fuzzy Clustering}

Kemunculan fuzzy clustering dilatarbelakangi adanya curse of dimensionality, yaitu jumlah aturan (rule) yang begitu cepat membesar dengan bertambahnya jumlah variabel input (Naba 2009). Jumlah rule yang begitu besar akan membuat komputasi menjadi berat dan juga optimasi parameter rule menjadi lebih sulit. Dengan fuzzy clustering, suatu data input-output akan dikelompokan dalam beberapa grup atau 
cluster. Informasi cluster ini akan membantu dalam pembentukan fuzzy inference system yang bisa memodelkan kelakuan hubungan input-output. Fuzzy clustering adalah salah satu teknik untuk menentukan cluster optimal dalam suatu ruang vektor. Fuzzy clustering sangat berguna bagi permodelan fuzzy terutama dalam mengidentifikasi aturan fuzzy.

Ada beberapa algoritma clustering data yaitu dengan Fuzzy C-Means (FCM) atau dengan menggunakan Subtractive Clustering. FCM adalah algoritma pengclusteran yang terawasi, sebab pada FCM terlebih dahulu harus mengetahui jumlah cluster yang akan dibentuk. Namun apabila jumlah cluster yang akan dibentuk belum diketahui sebelumnya, maka harus menggunakan algoritma yang tidak terawasi yaiu subtractive clustering. Subtractive clustering didasarkan atas ukuran densitas titik-titik data dalam suatu ruang.

\section{METODA PENELITIAN}

Data time series dari kelima variabel makroekonomi Indonesia dimulai dari 2001 1 hingga 2011 . Data tersebut kemudian di konversi ke dalam bentuk matriks berukuran [123x5] (123 baris dan 5 kolom). Untuk menyeragamkan periodisasi data pengamatan, maka data PDB yang semula dalam bentuk kuartalan akan dipecah menjadi data bulanan dengan menggunakan metoda cubic spline interpolation. Setelah memperoleh data PDB bulanan, selanjutnya adalah mengestimasi output potensial dari nilai PDB dengan menggunakan HP-Filter.

Dari matriks [123x5] akan dibagi ke dalam dua bagian yaitu data input dan data output. Data input terdiri dari empat variabel yaitu nilai tukar, uang beredar, suku bunga PUAB dan output gap. Sedangkan data outputnya adalah inflasi. Sehingga akan terdapat dua matriks yaitu matriks input [123x4] dan matriks output [123x1].

Berikut ringkasan keterangan atas data yang digunakan dalam penelitian ini.

Tabel 2

Data dan Variabel yang Digunakan

\begin{tabular}{|c|c|c|}
\hline Data & Variabel & Sumber \\
\hline Nilai Tukar Rp/USD & Input1 & $\begin{array}{l}\text { http://sauder.ubc.ca University of British } \\
\text { Columbia }\end{array}$ \\
\hline Uang Beredar $\left(\mathrm{M}_{2}\right)$ & Input2 & $\begin{array}{l}\text { Statistik Ekonomi dan } \\
\text { Indonesia (SEKI) }\end{array}$ \\
\hline Suku Bunga PUAB & Input3 & $\begin{array}{l}\text { Statistik Ekonomi dan Keuangan } \\
\text { Indonesia (SEKI) }\end{array}$ \\
\hline Output Gap & Input4 & $\begin{array}{l}\text { Diolah oleh penulis melalui estimasi HP } \\
\text { Filter }\end{array}$ \\
\hline Inflasi & Output1 & Badan Pusat Statistik \\
\hline
\end{tabular}

Metoda yang digunakan dalam mengestimasi tingkat inflasi adalah metoda ANFIS (Adaptive Neuro Fuzzy Inference System). Metoda ini dipilih karena beberapa landasan ilmiah di antaranya.

1) The Mathworks Inc (2002) menjelaskan:

"ANFIS derives its name from adaptive neuro-fuzzy inferencesystem. Using a given input/output data set, the toolbox function anfisconstructs a fuzzy inference system (FIS) whose membership 
functionparameters are tuned (adjusted) using either a backpropagation algorithmalone, or in combination with a least squares type of method. This allows yourfuzzy systems to learn from the data they are modeling."

2) Naba (2009) dalam bukunya mengatakan bahwa:

"Dalam permodelan berdasar data, ada situasi dimana kita sama sekali tidak bisa meraba bagaimana seharusnya bentu fungsi keanggotaan yang cocok untuk dipakai dalam pemetaan input menjadi output. Dengan mengatur parameter fungsi keanggotaan, itu akan membuang-buang waktu saja karena cenderung mengarah ke trials-errors, tanpa prosedur yang jelas dan sistematis. Disinilah letak peran ANFIS yang bekerja berdasar teknik pembelajaran neuro adaptive. ANFIS bekerja secara iteratif menebak parameter fungsi keanggotaan yang cocok."

3) Kusumadewi (2002) dalam bukunya mengatakan bahwa:

“...ANFIS adalah suatu metoda yang mana dalam melakukan penyetelan aturan menggunakan algoritma pembelajaran terhadap data. ...ANFIS juga memungkinkan aturan-aturan untuk beradaptasi."

4) Fariza et al. (2007) dalam penelitiannya Performasi Neuro Fuzzy untuk Peramalan Time Series, metoda ANFIS menghasilkan proses belajar yang baik dimana nilai error training data mampu mencapai 0 (nol).

Dalam memodelkan ANFIS, penulis menggunakan aplikasi Matlab versi R2009a. MatLab (Matrix Laboratory) merupakan suatu program komputer yang bisa membantu memecahkan berbagai masalah matematis yang kerap ditemui dalam bidang teknis.

Proses implementasi adaptive neuro fuzzy yang digunakan dalam proses estimasi output (tingkat inflasi) memiliki urutan-urutan sebagai berikut.

1) Persiapan Data Time Series

Di dalam persiapan data time series, data time series tersebut dibentuk matriks yang memiliki pola input-output pada bagian kolomnya.

2) Setting Parameter dan Pembentukan Fuzzy Model

Tahap ini merupakan tahap penentuan tipe fungsi keanggotaan, jumlah fungsi keanggotaan masing-masing input dan data yang dilatihkan. Dari hasil setting parameter fuzzy kemudian akan dibentuk fuzzy modelnya, pada tahap ini akan dibentuk fuzzy model sugeno dengan parameter yang telah ditentukan sebelumnya.

3) Learning Adaptive Neuro Fuzzy

Pada tahap ini, akan dibelajarkan data pelatihan pada adaptive neuro fuzzy yang akan menghasilkan sebuah matriks output, kemudian dari matriks ini akan digunakan untuk proses estimasi.

4) Output Adaptive Neuro Fuzzy

Output dari adaptive neuro fuzzy akan berupa grafik yang berisi kurva dari data aktual dan data hasil prediksi neuro fuzzy, sehingga dari hasil proses pembelajaran data maka akan ditemukan model untuk mengestimasikan output dengan hanya merubah parameter pada fungsi keanggotaan. 


\section{ANALISIS DAN PEMBAHASAN}

\section{Data Makroekonomi}

Gambar 1 sampai 4 (Lampiran 1) menunjukkan data PDB kuartalan yang sudah diinterpolasi ke dalam bentuk data PDB bulanan dan data PDB potensial yang sudah diestimasi dengan metoda HP-Filter.

Dengan melihat matriks data yang berukuran $123 \times 5$ maka untuk menghindari curse of dimentionality seperti yang telah dijelaskan sebelumnya, maka pengidentifikasian aturan fuzzy serta setting parameter dalam pembentukan fuzzy inference system dalam penelitian ini menggunakan algoritma subtractive clustering. Clustering ini digunakan untuk mengidentifikasi aturan-aturan fuzzy yang bisa memodelkan kelakuan hubungan data input-output dengan jumlah rule minimum.

\section{Implementasi ANFIS}

Terdapat 9 data cluster dari matriks berukuran 123x5, dan menghasilkan 9 aturan fuzzy yang membentuk model fuzzy. Pada arsitektur ANFIS aturan fuzzy akan berbentuk aturan fuzzy sugeno seperti yang terlihat berikut ini.

[R1] if(Rp is in1cluster1).(M2 is in2cluster1).(PUAB is in3cluster1).(Gap is in4cluster1) then (Inflasi is out1cluster1)

[R2] if(Rp is in1cluster2).(M2 is in2cluster2).(PUAB is in3cluster2).(Gap is in4cluster2) then (Inflasi is outlcluster2)

[R3] if(Rp is inlcluster3).(M2 is in2cluster3).(PUAB is in3cluster3).(Gap is in4cluster3) then (Inflasi is out1cluster3)

[R4] if(Rp is in1cluster4).(M2 is in2cluster4).(PUAB is in3cluster4).(Gap is in4cluster4) then (Inflasi is out1cluster4)

[R5] if(Rp is inlcluster5).(M2 is in2cluster5).(PUAB is in3cluster5).(Gap is in4cluster5) then (Inflasi is out1cluster5)

[R6] if(Rp is in1cluster6).(M2 is in2cluster6).(PUAB is in3cluster6).(Gap is in4cluster6) then (Inflasi is out1cluster6)

[R7] if(Rp is in1cluster7).(M2 is in2cluster7).(PUAB is in3cluster7).(Gap is in4cluster7) then (Inflasi is outlcluster7)

[R8] if(Rp is in1cluster8).(M2 is in2cluster8).(PUAB is in3cluster8).(Gap is in4cluster8) then (Inflasi is out1cluster8)

[R9] if(Rp is in1cluster9).(M2 is in2cluster9).(PUAB is in3cluster9).(Gap is in4cluster9) then (Inflasi is out1cluster9)

Setelah aturan fuzzy terbentuk, selanjutnya adalah melakukan pengecekan atas aturan tersebut. Pengecekan dilakukan dengan menggunakan data dari 20091 hingga 20113. Tabel 3 (Lampiran 1) menunjukkan hasil pengecekan data. 
Tabel menyajikan, nilai rata-rata error sebesar 0,6031 hal ini menggambarkan hasil estimasi dari data dengan ANFIS bisa dikatakan memiliki tingkat akurasi hasil yang cukup tinggi.

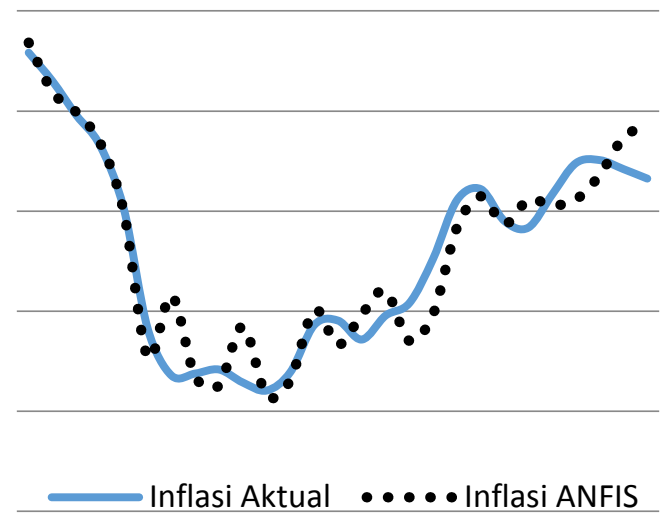

Gambar 6

Hasil Estimasi ANFIS

Gambar 6 menunjukkan perbandingan hasil output inflasi model adaptive neuro fuzzy dengan inflasi aktual, terlihat hanya beberapa titik perbedaan hasil antara estimasi dengan aktual. Namun secara keseluruhan model mampu menerangkan hubungan input-output dengan baik. Hal ini ditunjukkan dengan pergerakan titik-titik mengikuti arah garis. Dari gambar 7 dapat dilihat selisih negatif terbesar adalah -1,60 dan positif terbesar adalah 1,11. Sedangkan error negatif terkecil adalah $-0,05$ dan positif terkecil adalah 0,06 .

Selisih negatif menunjukkan bahwa hasil estimasi yang terlalu besar terhadap inflasi aktualnya. Sedangkan selisih positif menunjukkan inflasi aktual yang lebih besar. Selisih negatif terbesar terjadi pada bulan Juli 2009, hal ini bisa terjadi karena tekanan inflasi pada tahun 2009 secara umum dan pada pertengahan 2009 khususnya cukup minimal. Hal ini disebabkan oleh nilai rupiah yang cenderung menguat dari periode-periode sebelumnya. Selisih positif 1,11 terjadi pada bulan Juni 2010 di picu oleh adanya gangguan dari sisi pasokan khususnya bahan makanan meningkat tajam akibat anomali cuaca baik ditingkat global maupun domestik. Kondisi tersebut memicu lonjakan harga komoditas pangan di pasar global dan dalam waktu bersamaan mempengaruhi pasar domestik. Komoditas bahan pokok seperti beras dan aneka bumbu memberi konstribusi kenaikan harga yang cukup signifikan. 


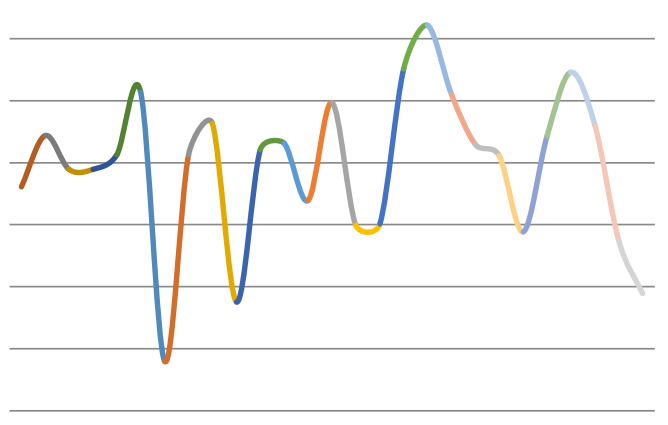

Gambar 7

Tingkat Selisih

\section{SIMPULAN DAN SARAN \\ Simpulan}

Berdasarkan hasil pembahasan yang telah dipaparkan pada bab sebelumnya mengenai pembentukan model estimasi inflasi dengan menggunakan empat variabel input (nilai tukar, uang beredar, PUAB dan output gap) dalam menjelaskan output (inflasi) dengan metoda adaptive neuro fuzzy maka pada bab ini ditarik beberapa kesimpulan atas analisis tersebut.

Permodelan ANFIS menghasilkan 9 aturan fuzzy yang bisa memodelkan kelakuan input-output antara variable makro ekonomi (Rp, M2, PUAB dan output gap) terhadap inflasi. Secara keseluruhan, Adaptive Neuro Fuzzy Inference System (ANFIS) mampu melakukan training atas data dan memodelkan kelakuan hubungan inputoutput dengan baik, hal ini dibuktikan dengan rata-rata tingkat error mampu mencapai 0 yaitu sebesar 0,6031 .

Dari hasil estimasi ini data training berhasil diuji dengan baik, hanya saja pada saat pengecekan data ada beberapa pasangan input-output yang mengalami selisih antara aktual dan estimasi yang cukup besar, selisih terbesar adalah -1,60 dan 1,11. Secara keseluruhan model ini masih dapat menjelaskan perilaku input-output.

\section{Saran}

Mengharapkan penelitian dengan model dan metoda yang sama terus dikembangkan agar memperoleh hasil yang sempurna pula. Beberapa saran untuk penelitian ke depan di antaranya:

1. Berkenaan dengan output gap, dalam penelitian ini penulis menggunakan metoda HP-Filter dalam mengestimasi nilai output potensial. Penggunaan metoda ini hanya berdasarkan kepopulerannya saja dan banyak digunakan, masih terdapat banyak metoda dalam mengestimasi output potensial. Untuk kedepannya tidak ada salahnya untuk mencoba metoda estimasi yang lain seperti Beveridge-Nelson 
decomposition, Unobserved Component, Structural VAR, dan Multivariate Hodrick-Prescott Filter.

2. Meski tingkat keakurasian hasil estimasi cukup baik dengan tingkat error yang kecil yaitu sebesar 0,6031, namun masih terdapat beberapa pasangan input-output yang mengalami error yang tinggi, kedepannya diharapkan untuk memperbaiki atau memperkecil tingkat error tersebut.

3. Dari hasil pembahasan, error tinggi yang timbul lebih disebabkan oleh faktor di luar variabel pengamatan, seperti pola tren suatu data dan variabel iklim. Ke depan diharapkan untuk melibatkan variabel-variabel di luar variabel makroekonomi itu sendiri.

\section{DAFTAR PUSTAKA}

Agung, J., S. Astiyah, E. Sukowati, N.J Prastowo, M.F Muttaqin, dan R. Ismail. 2003. "Identifikasi variabel informasi dalam framework inflation targeting." Buletin Ekonomi Moneter dan Perbankan 6 (3): 59-77. https://doi.org/https://doi.org/10.21098/bemp.v6i3.331.

Fariza, Arna, Afrida Helen, dan Annisa Rasyid. 2007. "Performansi neuro fuzzy untuk peramalan data time series." In Seminar Nasional Aplikasi Teknologi Informasi, 77-82.

Kusumadewi, S. 2002. Analisis dan desain sistem fuzzy menggunakan tollbox matlab. Yogyakarta: Graha Ilmu.

Manurung, M., dan P. Rahardja. 2004. Uang, perbankan, dan ekonomi moneter (kajian kontekstual Indonesia). Jakarta: Fakultas Ekonomi Universitas Indonesia.

Naba, E. A. 2009. Belajar cepat fuzzy logic menggunakan matlab. Yogyakarta: Andi Offset.

The, Mathworks Inc. 2002. Fuzzy logic toolbox user's guide. The Mathworks Inc.

Tjahjono, E.D, H. Munandar, dan J. Waluyo. 2010. "Revisiting estimasi potential output dan output gap Indonesia: Pendekatan fungsi produksi berbasis model."

Yuliadi, I. 2008. Ekonomi Moneter. Jakarta: Indeks. 


\section{LAMPIRAN 1}

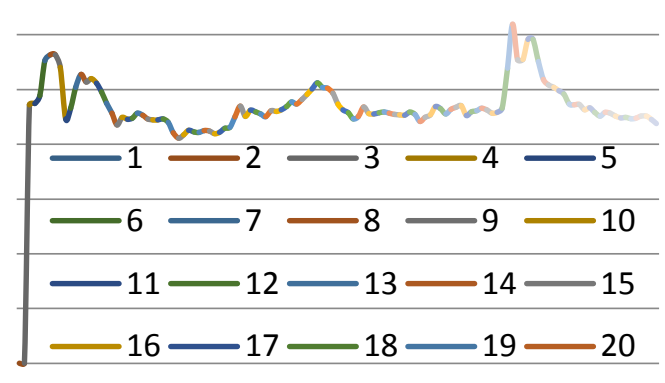

Gambar 1

Nilai Tukar Rp/USD

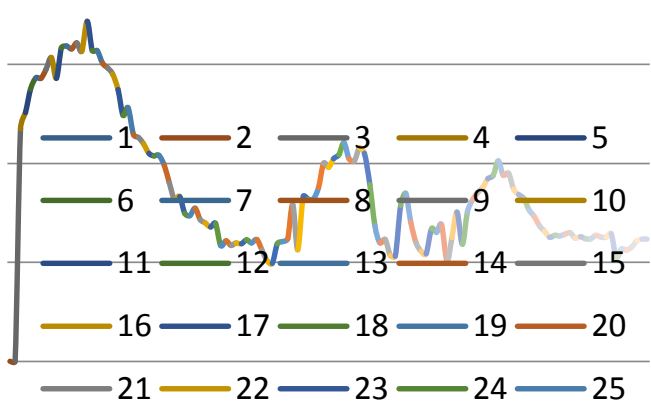

Gambar 3

Suku Bunga PUAB

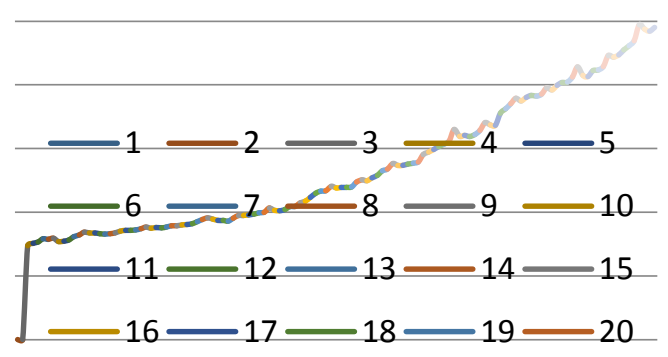

Gambar 2

Jumlah Uang Beredar (Miliaran Rp)

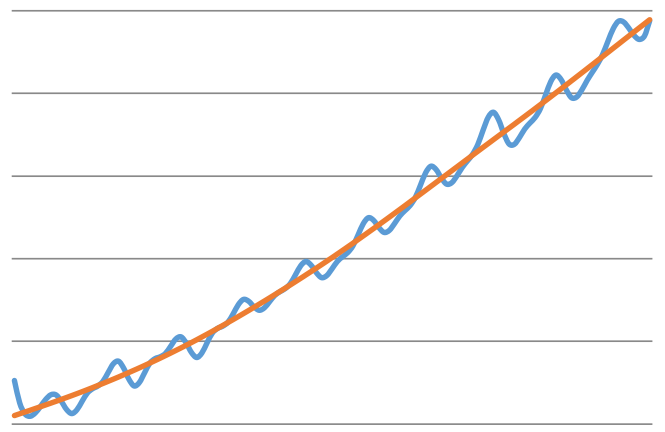

$\longrightarrow$ PDB Aktual —PDB Potensial

Gambar 4

PDB Aktual dan Potensial (Triliunan Rp)

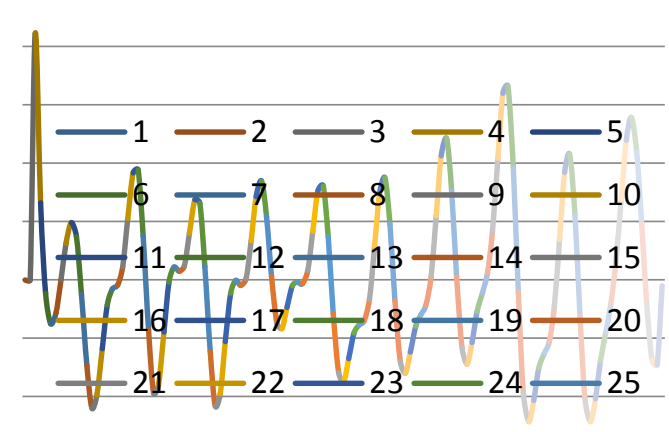

Gambar 5

Output Gap 20011 -20113 
Tabel 3

Hasil Estimasi Inflasi

\begin{tabular}{|c|c|c|c|c|}
\hline \multicolumn{2}{|c|}{ Periode } & \multirow{2}{*}{$\frac{\text { Inflasi Aktual }}{9,17}$} & \multirow{2}{*}{$\begin{array}{c}\text { Inflasi ANFIS } \\
9,37\end{array}$} & \multirow{2}{*}{$\begin{array}{c}\text { Selisih } \\
-0,20\end{array}$} \\
\hline 2009 & 1 & & & \\
\hline & 2 & 8,60 & 8,38 & 0,22 \\
\hline & 3 & 7,92 & 7,97 & $-0,05$ \\
\hline & 4 & 7,31 & 7,36 & $-0,05$ \\
\hline & 5 & 6,04 & 5,98 & 0,06 \\
\hline & 6 & 3,65 & 3,08 & 0,57 \\
\hline & 7 & 2,71 & 4,31 & $-1,60$ \\
\hline & 8 & 2,75 & 2,69 & 0,06 \\
\hline & 9 & 2,83 & 2,51 & 0,32 \\
\hline & 10 & 2,57 & 3,69 & $-1,12$ \\
\hline & 11 & 2,41 & 2,31 & 0,10 \\
\hline & 12 & 2,78 & 2,62 & 0,16 \\
\hline \multirow[t]{12}{*}{2010} & 1 & 3,72 & 4,02 & $-0,30$ \\
\hline & 2 & 3,81 & 3,33 & 0,48 \\
\hline & 3 & 3,43 & 3,93 & $-0,50$ \\
\hline & 4 & 3,91 & 4,40 & $-0,49$ \\
\hline & 5 & 4,16 & 3,40 & 0,76 \\
\hline & 6 & 5,05 & 3,94 & 1,11 \\
\hline & 7 & 6,22 & 5,67 & 0,55 \\
\hline & 8 & 6,44 & 6,29 & 0,15 \\
\hline & 9 & 5,80 & 5,74 & 0,06 \\
\hline & 10 & 5,67 & 6,23 & $-0,56$ \\
\hline & 11 & 6,33 & 6,11 & 0,22 \\
\hline & 12 & 6,96 & 6,23 & 0,73 \\
\hline \multirow[t]{3}{*}{2011} & 1 & 7,02 & 6,72 & 0,30 \\
\hline & 2 & 6,84 & 7,47 & $-0,63$ \\
\hline & 3 & 6,65 & 7,70 & $-1,05$ \\
\hline
\end{tabular}

